\title{
Animal Handling during Supply for Marketing and Operations at an Abattoir in Developing Country: The Case of Gudar Market and Ambo Abattoir, Ethiopia
}

\author{
Fufa S. Bulitta, Girma Gebresenbet ${ }^{*}$, Techane Bosona \\ Department of Energy and Technology, Swedish University of Agricultural Sciences, Uppsala, Sweden. \\ Email: "girma.gebresenbet@slu.se
}

Received December $3^{\text {rd }}, 2011$; revised January $16^{\text {th }}, 2012$; accepted January $29^{\text {th }}, 2012$

\begin{abstract}
In the agricultural sector, it is important to appropriately develop livestock resources in of developing countries in order to reduce poverty. The aim of this study was to investigate the animal handling and welfare issues during transport for marketing with special focus on cattle flow to and from Gudar livestock market and activity chain of Ambo abattoir in Ethiopia. Information and data on main feeder markets to Gudar regional market; the main stakeholders in this animal supply chain; number of animals flow to and from Gudar market; the distance and time duration the animals transported; animal handling and welfare concerns during transport and at market site; and activities in Ambo abattoir chain were gathered, interpreted and discussed. The study indicated that the flow of cattle to and from Gudar market was by walking which took up to 4 days or by vehicles which took up to $3 \mathrm{~h}$. There were no appropriate vehicle and loading facilities and animal handling conditions were poor. From total number of animals supplied to Gudar market about 7.6\% died, 6.9\% injured and 2.8\% was stolen during transport. During transport from Gudar to final destination by walking, about $16 \%$ died and $10.7 \%$ was injured. The effect of animal number $(p=0.0498)$ was slightly significant than the effect of travel distance $(p=0.3487)$ on the occurrence of incidences such as animal death and injuries, at significance level of 0.05. Lameness and injury to bone, muscle, swelling of leg and sickness were widely observed during transportation by walking. Poor market infrastructures; lack of regional abattoir facilities; difficulties in getting timely market information; and lack of well-organized networks between stakeholders were also identified as existing problems compromising the animal welfare and economic benefits. Therefore, further research works concerning animal welfare during animal flow in the supply chain; and impact of abattoir activities on environment and human and animal health should be conducted. Such studies important to improve the economic benefits gained from livestock resources with positive contribution towards efforts of insuring food security and sustainable development.
\end{abstract}

Keywords: Ethiopia; Animal Handling; Supply Chain; Animal Welfare; Livestock Market

\section{Introduction}

Ethiopia has suitable environment for the production of livestock (farm animals) and it ranks $1^{\text {st }}$ in Africa and $10^{\text {th }}$ in the world in population of livestock [1]. Studies by Solomon et al. [2] indicated that, there are about 35 million cattle, 39 million goats and 1 million camels in Ethiopia. The authors also mentioned that, the estimated growth rate for cattle in Ethiopia is $1.1 \%$. Although Ethiopia has great potential of livestock resources, the animal production and marketing systems in the country are only for subsistence; the productivity rate is low; and the livestock marketing system is not progressed [3]. To improve this, the infrastructures in transport and marketing and communication sectors should be developed [3].

*Corresponding author.
During the period of 1996/97 up to 1999/2000, the number of animals sold in Finfinnee city market was 35,000 to 60,000 and $65 \%$ of the cattle supplied to Finfinnee city market constituted fattened animals such as oxen and cows [4]. One of livestock markets from where cattle are bought and transported to Finifinnee market is Gudar regional market.

In the agricultural sector, animal supply chain management is complex process as it is related to animal welfare and subsequent meat quality and safety issues [5]. In the animal flow to livestock markets or abattoirs, poor handling and long transport impose stress on animals. In most developed countries, animals are transported more or less by using standardized transport vehicles. However, in developing countries, animal transport is mostly by walking from farm to marketing or by ordinary trucks not 
designed for animal transport. Even in developed countries, loading and unloading are very stressful procedures to animals [6] and loading takes usually more time than unloading [7].

For more understanding of animals' welfare there are scientific definitions, first formulated by the UK Farm Animal Welfare Council (FAWC) [8,9]. These definitions known as "Five Freedoms of Animal Welfare" include: freedom from hunger and thirst; freedom from pain, injury and disease; freedom from fear and distress; freedom from discomfort; and freedom to express normal behaviour. These definitions create logical and comprehensive framework for analysis of welfare.

In developing countries like Ethiopia, long distance journey; forcing animals to cross big rivers that have no bridge; and journey without sufficient food water and resting time cause stress to animals. Animals are also exposed to high radiation in summer and heavy rain in the winter. Animals are transported from farms to market or other places usually by walking or by inappropriate vehicles (designed for goods transport). Animal handlers during transport and marketing are not trained and don't have sufficient knowledge and understanding about the welfare of animals during transport and pre-transport and post-transport. In general, poor animal handling results in loss of weight, physical injuries, sickness and even death of animals, leading to the poor welfare conditions and economic loss of the stakeholders and the country as whole $[10,11]$.

The overall objective of the current study was to investigate the animal handling and welfare issues during transport for marketing with special focus on cattle flow to and from Gudar livestock market and activity chain of Ambo abattoir in Ethiopia. The specific objectives were to:

- Identify the main stakeholders involved in this animal supply chain and their access to information;

- Map out the animal flow and marketing conditions in the study area;

- Investigate the animals handling and welfare conditions during transport and at Gudar market;

- Map out the activity chain of Ambo abattoir.

\section{Methodology}

\subsection{Study Area}

Gudar livestock market is located at $8^{\circ} 58^{\prime} 30 " \mathrm{~N}$ latitude and $37^{\circ} 45^{\prime} 58^{\prime \prime E}$ longitude in Oromia regional state, Ethiopia.

Gudar is the biggest animal market in western Oromia which is $126 \mathrm{~km}$ from Finfinnee city and it has 8 feeder regional livestock markets such as Fincha, Shambu, Bakko, Nonno, Danno, Shoboka, Gedo and Xuqurhincinni mar- kets (see Figure 1). Animals bought from Gudar market are transported to Finfinnee city market passing through Ambo, Ginchi, Olankami, and Holota markets. In this study, the livestock markets have been classified as primary, feeder and regional market. Primary markets are those markets where animals were produced or originated. Feeder markets are markets where group- 1 traders (traders who buy animals from feeder markets and sell at Gudar regional market) have direct contact with farmers or traders in primary market (see Figure 1). The regional market is (e.g. Gudar market) where animal from different feeder markets including primary markets are sold.

The Gudar cattle market is the main source of slaughter animals for abattoirs in the nearby cities such as Ambo city. For example slaughter animals supplied to Ambo abattoir (about $12 \mathrm{~km}$ away from the Gudar market) which mostly provides services for butcheries, institutions, hotels and restaurants, are bought from farmers and traders at Gudar market.

\subsection{Main Stakeholders Involved in the Supply Chain and the Animals Considered}

In this animal supply chain, the study was focused on two main stakeholders, i.e. farmers and traders. Traders are categorized in to two: Category-1 and Category-2. Traders in the Category- 1 are those who participate in feeder markets whereas Category-2 traders are those who participate in regional market. The marketing activities at regional market are between farmers, institutions, traders, butcheries, and hotel or restaurant owners. The involvement of other stakeholders such as governmental institutions, transport companies, and abattoirs were limited.

Although the Gudar market is used for marketing animals including sheep, goats, donkeys and horses, this study focused mainly on cattle. Most of the animals that were found at Gudar market were oxen, bulls, cows and heifers. At Gudar market, animals were categorized in to four groups (see Figure 1). G1-animals were those bought from different feeder markets and transported to Gudar market by traders; G2-animals were those brought by farmers from vicinities of Gudar; G3-animals were those bought from Gudar market by traders and to be transported to Finfinnee; G4-animals were those bought from Gudar market by farmers and traders for consumption purpose, for instance in butcheries, hotels, institutions and restaurants at Gudar area.

\subsection{Data Collection}

Data and information were collected through interviews and questionnaires. Information was gathered from key informants such as farmers, traders, and workers of Ambo Abattoir, tax collectors and butcheries. Data on number 


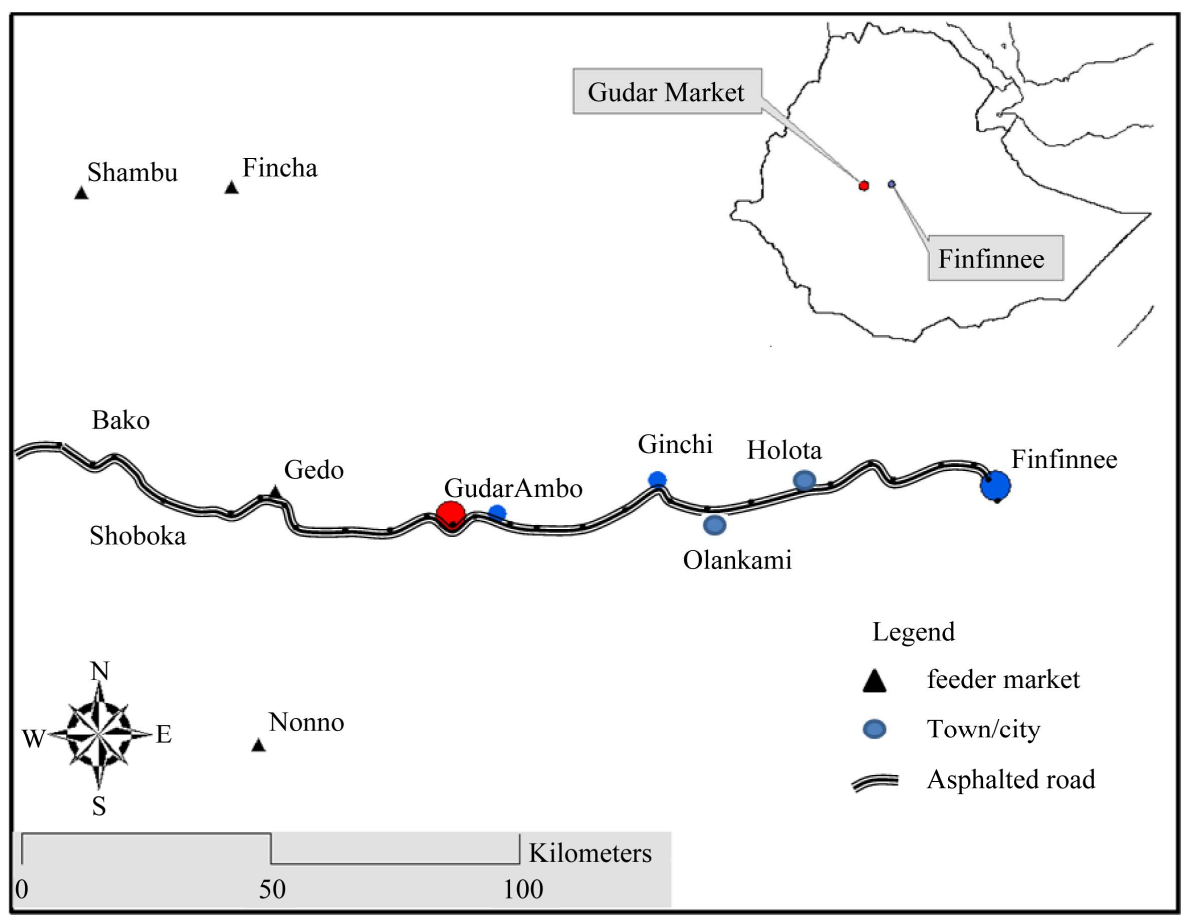

(a) Location of study area

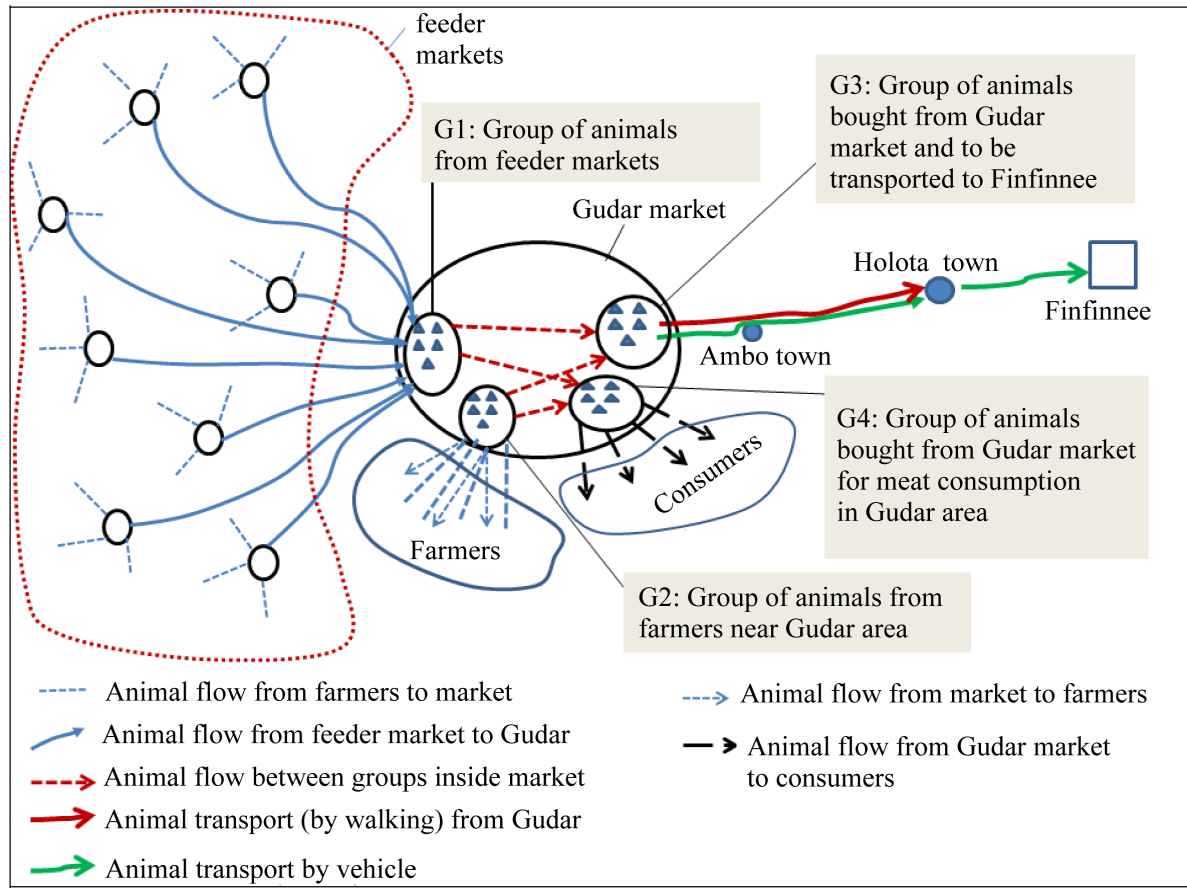

(b) Animal supply chain to and from Gudar market

Figure 1. Animal flow to and from Gudar livestock market (a) Location of Gudar livestock market and some feeder markets (Shambu, Fincha, Gedo, and Nonno) on the map of Ethiopia; (b) Animal supply chain from the source to end users through Gudar market.

of animals flow to and from Gudar market per market day; the distance animals walked and time duration the animals walked to reach Gudar market; animal handling conditions during transport and at market site; and the well identified feeder markets to Gudar regional market were gathered and used. The number of animals brought 
to Gudar market was recorded for three market days. In addition, interviews were made with tax collectors at the market gate.

In order to investigate the occurrence of incidences such as death and injuries of animals during transport, more detailed information was gathered from 21 of the traders who purchased animals from feeder markets and transported to Gudar market. Similar information was gathered from 3 of traders who purchased animals from Gudar market and transported to Finifinne. In addition to conducting interviews, physical observations were made and animal conditions and handling of animals at the market, as well as during loading activities were recorded. The physical observations were also made to register the activities in the Ambo abattoir chain.

\section{Results}

\subsection{Characteristics of Stakeholders and Their Access to Information}

In this study, the main stakeholders were farmers and animal traders. Farmers sell their animals directly to the consumers and traders in the market. Based on the collected data, Figure 2 indicates that the farmers sell their animals to buy fertilizer; to pay the expenses for their children; to buy seeds; to cover payments for social activities or events; and to fulfill their families' interest to buy food, cloth and for other necessities. There is no well-established market information system for farmers and traders. However, traders had better information access about marketing situations and price than farmers because the traders had more relationship with other traders, clients or they had their own better experiences.

This indicates that farmers usually go to market without recent price information, even though the price of animals fluctuates depending on the number of animals available in the market, the seasonal conditions, and traders available in the market (and their capital ability to buy). It was observed that the number of traders in the market and their capital ability and the number of animals in the market could influence the price of animals.

\subsection{Characteristics of the Animal Supply to and from Gudar Cattle Market}

The animals were first brought from their origin (farms) to feeder markets by farmers and then traders bought and transported to Gudar market (see Figure 1). From feeder markets they were transported to Gudar market mostly by walking and arrived after journey of one or more days depending on the distance between the feeder market and Gudar regional market (see Figure 1).

The number of animals at the market varied from one market date to another and from available data, the num-

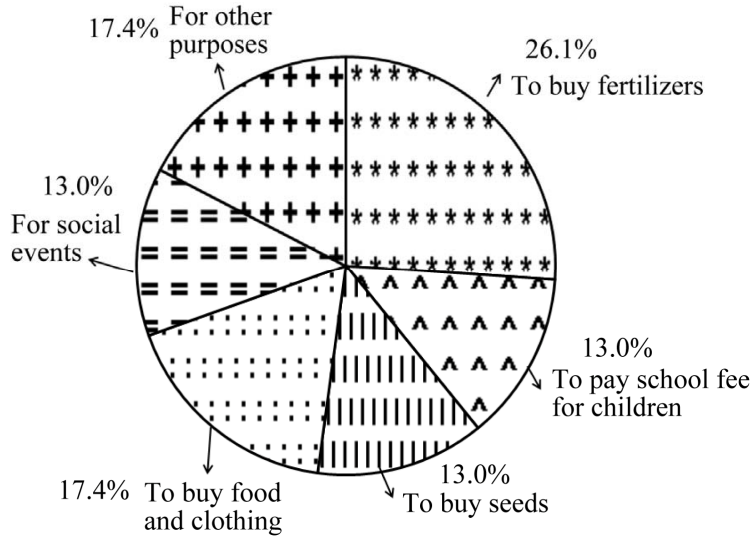

Figure 2. Reasons of selling animals, expressed in number of farmers, \%. The estimation was based on information obtained from 10 farmers.

ber of animals supplied to Gudar market per market day was estimated to be between 1000 and 2000. The data collected during three consecutive market days showed that oxen were the most dominating in number while heifers were the least in the market (see Figure 3).

Table 1 presents the recorded flow of animals from the vicinity of Gudar town. The cattle were brought from farms with average distance of $13 \mathrm{~km}$, varying from $1 \mathrm{~km}$ to $19 \mathrm{~km}$ and they walked for 1 to $6 \mathrm{~h}$.

Some of the regional markets such as Bakko, Shoboka and Gedo are connected to Gudar market by asphalted road. Animals from these areas could be transported to Gudar market by vehicle which could take a maximum of $2 \mathrm{~h}$ instead of walking for many days on foot (see Figure 4). The farthest regional markets from Gudar market are Fincha and Shambu markets which are about $158 \mathrm{~km}$ and $180 \mathrm{~km}$ away from Gudar respectively. From these feeder markets to Gudar, the animals were transported only by walking for more than 3 days (see Table 2).

The animals bought from Gudar market were transported from Gudar to Finfinnee city market both by vehicle and walking. Transporting animals by vehicle took $3 \mathrm{~h}$ whereas it took from 3 to 4 days by walking to reach Finfinne city market (see Table 3 ). In some cases the traders sell some of the animals on the way to Finfinne, until the animals reach Holota market. After Holota, all animals were transported to Finfinne city market by vehicle. The number of animals loaded per vehicle varied between 11 and 17 depending on the size and type of the vehicle.

\subsection{Animal Handling and Welfare Conditions}

During transport by vehicle from Gudar market, the animals were exposed to radiation; had no enough space on the vehicle; were tied by rope to the side of the vehicle and the animals were swaying here and there due 
Animal Handling during Supply for Marketing and Operations at an Abattoir in Developing Country:

The Case of Gudar Market and Ambo Abattoir, Ethiopia

Table 1. Animals flow to Gudar market from its vicinity.

\begin{tabular}{|c|c|c|c|}
\hline Animal category & No. of animals brought to market & Estimated distance, $[\mathrm{Km}]$ & Time taken for transport, [h] \\
\hline Farmer-1 & 2-oxen & 14 & 4 \\
\hline Farmer-2 & $1-\mathrm{ox}$ & 12 & 3 \\
\hline Farmer-3 & 3-oxen & 15 & 4 \\
\hline Farmer-4 & 2-oxen & 6 & 1 \\
\hline Farmer-5 & 3-cows & 9 & 2 \\
\hline Farmer-6 & 1-heifer & 8 & 2 \\
\hline Farmer-7 & 3-bulls & 8 & 2 \\
\hline Farmer-8 & 1-bull & 11 & 3 \\
\hline Farmer-9 & 2-heifer & 7 & 2 \\
\hline Farmer-10 & 2-cows & 17 & 5 \\
\hline Farmer-11 & 2-cows & 12 & 3 \\
\hline Farmer-12 & 1-bulls & 15 & 4 \\
\hline Farmer-13 & 2-heifer & 14 & 4 \\
\hline Farmer-14 & 1-heifer & 13 & 4 \\
\hline Farmer-15 & 2-oxen & 16 & 5 \\
\hline Farmer-16 & 3-cows & 14 & 4 \\
\hline Farmer-17 & 2-bulls & 9 & 2 \\
\hline Farmer-18 & 3-oxen & 10 & 2 \\
\hline Farmer-19 & 2-heifers & 15 & 4 \\
\hline Farmer-20 & 3-bulls & 15 & 4 \\
\hline Farmer-21 & 1-cow & 6 & 1 \\
\hline Farmer-22 & 3-bulls & 16 & 5 \\
\hline Farmer-23 & 1-bulls & 16 & 5 \\
\hline Farmer-24 & 2-heifers & 16 & 5 \\
\hline Farmer-25 & 1-heifer & 16 & 5 \\
\hline Farmer-26 & 2-oxen & 19 & 6 \\
\hline Farmers-27 & 3-cows & 19 & 6 \\
\hline Farmer-28 & 2-bulls & 19 & 6 \\
\hline Farmer-29 & 3-oxen & 19 & 6 \\
\hline Mean & & 13.3 & 3.8 \\
\hline $\mathrm{SD} \pm$ & & 4 & 1.5 \\
\hline
\end{tabular}

Table 2. Distances of feeder markets from Gudar and the travel time.

\begin{tabular}{|c|c|c|c|c|c|c|}
\hline \multirow{2}{*}{ Regional market } & \multicolumn{2}{|c|}{ From Farm to Gudar Market } & \multicolumn{2}{|c|}{ From Farm to Finfinne (only walking) ${ }^{\mathrm{a}}$} & \multicolumn{2}{|c|}{ From Farm to Finfinne (walking and vehicle) } \\
\hline & Distance $[\mathrm{km}]$ & Time $[\mathrm{h}]$ & Distance $[\mathrm{km}]$ & Time $[\mathrm{h}]$ & Distance $[\mathrm{km}]$ & Time $[\mathrm{h}]$ \\
\hline Fincha & 171 & 52 & 297 & 83 & 347 & 88 \\
\hline Shambo & 193 & 64 & 319 & 95 & 369 & 100 \\
\hline Bako & 126 & 40 & 252 & 71 & 302 & 76 \\
\hline Shoboka & 114 & 34 & 240 & 65 & 290 & 70 \\
\hline Geedoo & 69 & 21 & 195 & 52 & 245 & 57 \\
\hline Nono & 71 & 22 & 197 & 53 & 247 & 58 \\
\hline Xuqur-hinchini & 41 & 13 & 167 & 44 & 217 & 49 \\
\hline Dano & 127 & 40 & 253 & 71 & 303 & 76 \\
\hline Gudar vicinity & 13 & 4 & 139 & 35 & 189 & 40 \\
\hline Mean & 91 & 33 & 229 & 63 & 279 & 68 \\
\hline $\mathrm{SD} \pm$ & 59 & 17 & 59 & 19 & 59 & 19 \\
\hline
\end{tabular}

${ }^{\mathrm{a}}$ From Gudar to Finfinne = $126 \mathrm{~km}$ and it takes about $31 \mathrm{~h}$ by walking; ${ }^{\mathrm{b}}$ Excluding resting time. 
Table 3. Distances with transport time from Gudar to finfinnee central market.

\begin{tabular}{ccc}
\hline $\begin{array}{c}\text { Markets on the } \\
\text { line to Finfinne }\end{array}$ & $\begin{array}{c}\text { Distance from } \\
\text { Gudar }[\mathbf{k m}]\end{array}$ & $\begin{array}{c}\text { Transport time by } \\
\text { walking, h }\end{array}$ \\
\hline Ambo & 12 & 3 \\
Ginchi & 47 & $12(24)$ \\
Ollankami & 58 & $14(26)$ \\
Holota & 93 & $24(72)$ \\
Finfinne & 126 & 3 (by vehicle) \\
\hline
\end{tabular}

*The figures in the bracket are transport time including marketing and resting time on the way.

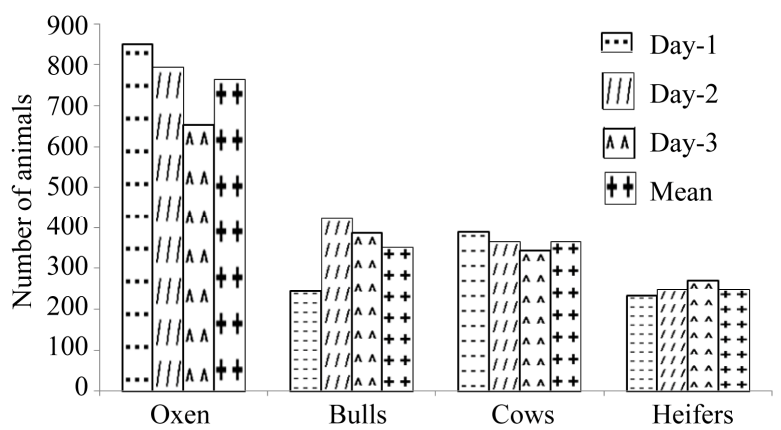

Figure 3. Number of animals at Gudar market during three consecutive market days.

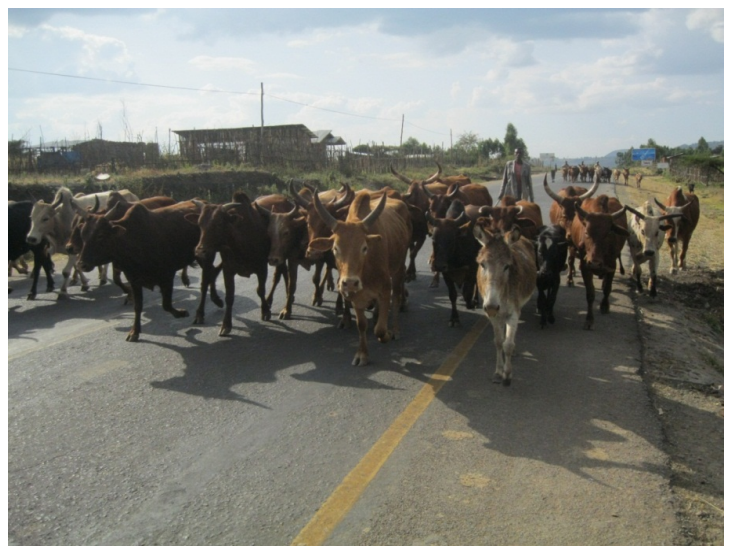

Figure 4. Animals transported from Gudar to Finfinnee city market by walking, exposed to traffic accidents.

to bad road and driving conditions. These conditions affected the welfare of the loaded animals. The trucks were not designed for animal transport and animals could jump and be damaged sometimes. Inside the vehicles, drivers used straw or wood chips to minimize chance of falling on the truck due to its slippery floor (see Figure 5).

In the market fence, it was observed that as soon as animal entered the market gate some animals showed behavioral changes such as becoming curious; ear or tail erecting; vocalizing; jumping here and there; refuse to

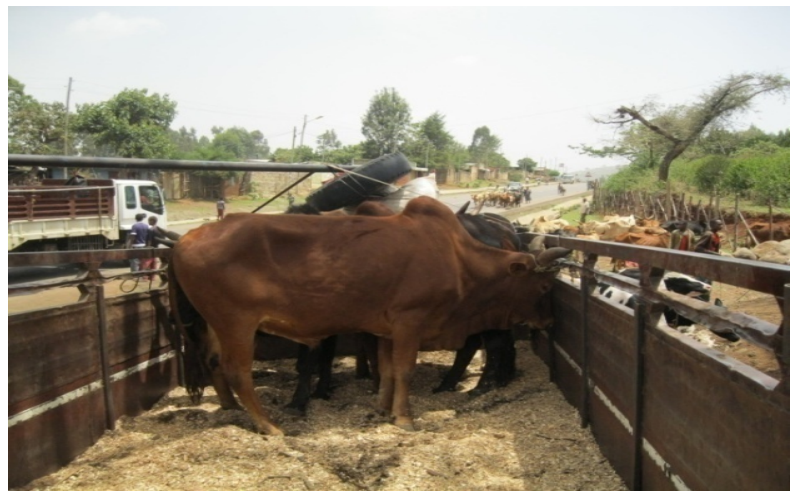

Figure 5. Animals tied to side of vehicle during transport from Gudar to Finfinnee.

move forward; running away; fighting against their handlers and against each other; urinating repeatedly; and being aggressive. Inside the fence, the surface of marketing area was rough and stony and should be cleared (see Figure 6). Animals felt uncomfortable and pain when they were transported on rocky and asphalted road full of gravels. Traffic accidents; the incidence of lameness and injury to bone and muscle; swelling of leg; and inflammation linked to infection during animal transportation by walking were observed problems. After walking for 2 to 3 days, some animals were tired; injured inside their foot; and became sick.

Based on the information obtained from 21 traders (three traders sourcing animal from each 7 feeder markets) and three traders who purchased animals from $\mathrm{Gu}-$ dar market and transported to Finfinne the incidence of animal death and injuries was investigated (see Figure 7). Totally these 21 traders supplied about 318 animals to Gudar per market day. The three traders purchased about 96 animals from Gudar and transported about 56 animals to Finfinne by walking, and transported the remaining 40 animals by vehicles. Considering 374 animals transported by walking, the effects of distance and number of animals on the occurrence of incidence were tested. From the statistical analysis of variance, the animals number had more effect ( $p=0.0498$ ) on the occurrence of animal death and injuries than the travel distance $(p=0.3487)$.

It was noticed that poor animal handling and inappropriate way of transporting animals increased the occurrence of incidences such as death and injuries. From the total number of animals $(n=318)$ transported to Gudar market from feeder markets, about $7.6 \%$ died on the way, about $1.6 \%$ died due to car accident, $6.9 \%$ injured and about $2.8 \%$ was stolen on the way (see Figure 7(a)). During transport by walking from Gudar to Finfinnee about $16 \%$ died $(7.1 \%$ due to car accident and $8.9 \%$ due to other reasons); and $10.7 \%$ injured on the way (see Figure 7(b)). 


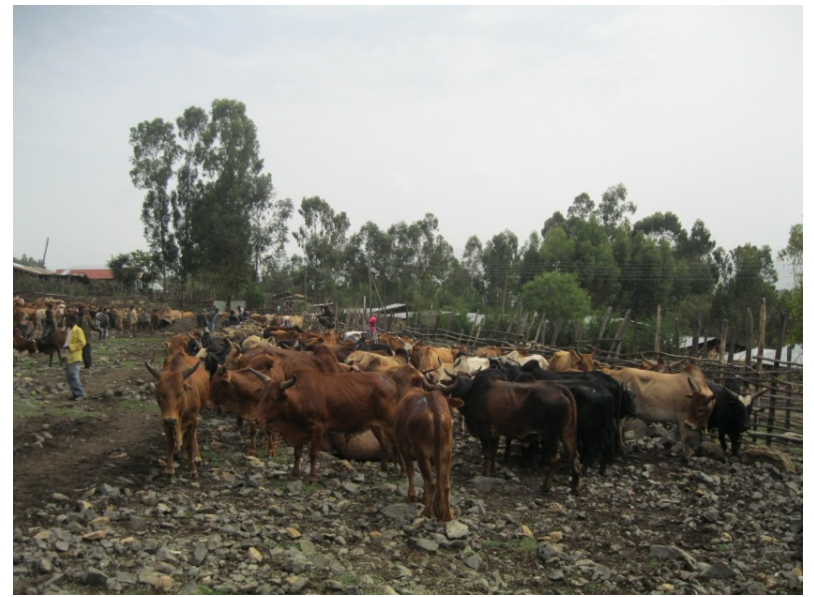

Figure 6. Groups of animals standing inside the fence of Gudar market which is full of sharp rocks.

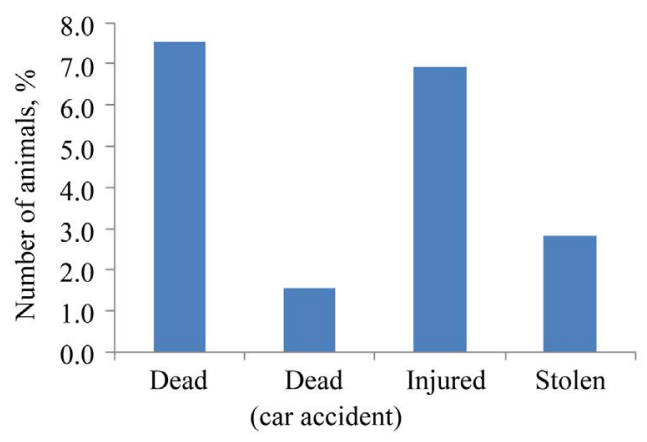

(a) Incidences during supply to Gudar

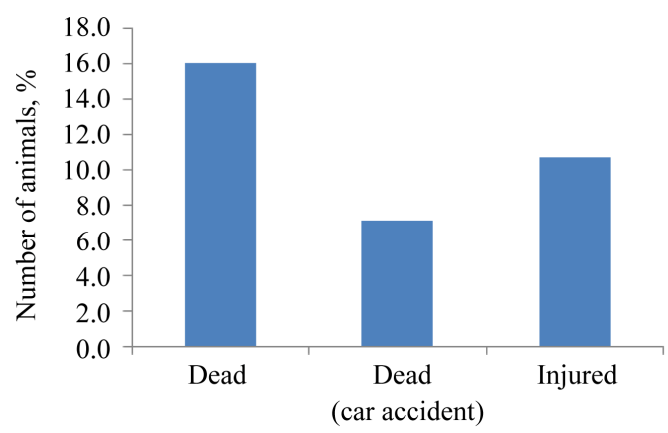

(b) Incidences during supply from Gudar to Finfinne

Figure 7. Incidences leading to poor animal welfare situations. (a) Number of dead, injured and stolen animals during transport from feeder markets to Gudar market, considering about 318 animals sourced from 7 regional markets by 21 traders per market day; (b) Number of dead and injured animals during transport from Gudar to Finfinne, considering about 56 animals purchased (by three traders) from Gudar per market day and transported to Finfinne by walking.

Loading place was found at about $2 \mathrm{~km}$ far from the Gudar market place. The loading ramp was poorly constructed by hilling and leveling the land (see Figure 8).

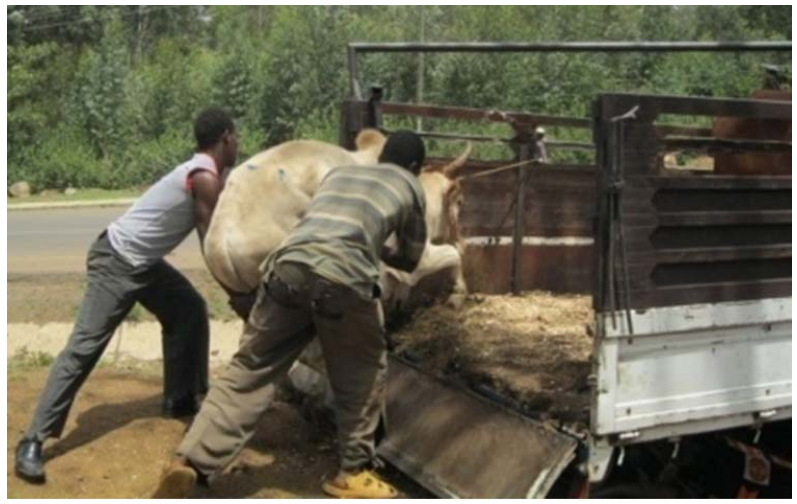

Figure 8. Animal loading processes at Gudar.

Its height was about $0.75 \mathrm{~m}$ and its dimensions were 2.6 $\mathrm{m}$ by $1.5 \mathrm{~m}$ and it was not suitable to load animals properly. This made the loading activity in Gudar market very stressful process.

During loading animal's horn or neck was tied by rope to pull towards the vehicle. It was observed that animal handlers beat the animals repeatedly or bend animals' tails forcefully if the animals refuse to be loaded. Some animals mounted the ramp and loaded quickly without pushing or pulling. For some animals the loading process was time consuming. Inside the vehicle, because of insufficient space, animal feel uncomfortable and can't stand with their normal position (see Figure 5). The main problems observed during transport towards Finfinne city market was lack of facility of loading ramp, standard of trucks, physical fatigue and injuries of animals.

\subsection{Activity Chain of Ambo Abattoir}

Activities in the Ambo abattoir chain were registered and mapped out as presented in Figure 9. The abattoir activity chain comprised of different operations such as animal delivery from market to stunning place; slaughter operation from stunning to evisceration; packaging and distribution of meat; delivery of skin to market; and waste disposal. Some of the animals delivered to the abattoir were very exhausted; injured, and tired mainly due to long journey and inhuman handling.

Veterinarian from Ambo agricultural bureau used to check body conditions and measure body temperature. Although inspection was done before and after slaughtering (to check the safety of meat), the abattoir lacked basic facilities which a standard abattoir should have. The abattoir had very traditional slaughter system, no cooling room, no machine operations (all activities were done manually). The stunning was done by traditional method by slaughtering animals with knife and skin lashing was done carelessly. The slaughtering days were Wednesday, Friday and Saturday. In average, fourteen 


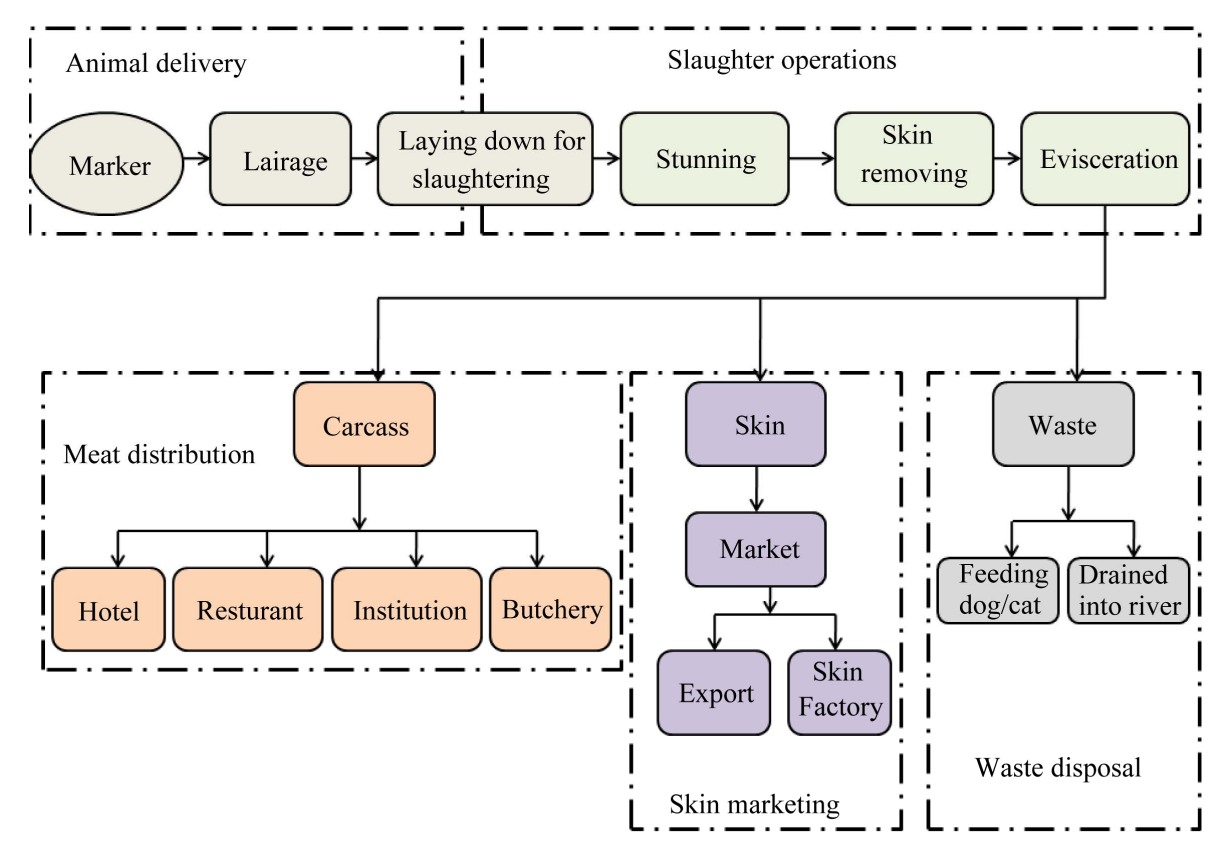

Figure 9. Activity chain of ambo abattoir.

animals were slaughtered per slaughter day. Carcasses are not held in refrigerated storage but suspended on hooks.

The meat was distributed to butcheries, hotels, restaurants, and institutions while the skin was sold at market from where it was transport to skin factories or prepared for export. Some solid wastes were used for feeding animals like dogs and cats. Bones and hooves were sometimes burnt at the abattoir site causing smoke resulting in bad smell and air pollution. The liquid waste was discharged to river which is the source of drinking water for animals and residences of Ambo town and surrounding farmers. This situation needs further investigation to improve the abattoir system and make residences free from water borne diseases as well as other diseases transmittable from animal to human.

\section{Discussion}

Although Ethiopia has high potential of livestock resource, it gains less economic benefit due to inefficient production and marketing systems. In order to increase the farmers as well as national income from livestock sector, market institutions and infrastructure (including roads and transporting facilities) as well as abattoir facilities should be developed [12]. It is important to develop the livestock sector to enhance insuring food security in addition to fulfilling immediate cash needs by farmers for paying fertilizers cost and other expenses.

The current study clearly showed that the animal welfare issue is serious problem which also leads to economic loss as a consequence. In this animal supply chain, animals bought from feeder markets such as Fincha and Shambu were transported first to Gudar market and then to Finfinnee. From farm, animals must walk for about $319 \mathrm{~km}$ to reach Finfinne which took upto 8 days. In some cases, vehicles were used to transport animals, especially from Gudar to Finfinnee. Such long journey and inhuman animal treatment during marketing, loading, transport, unloading and slaughtering have impact not only on animal welfare but also on meat quality. There were no appropriate loading facilities and the vehicles were not designed for animal transport. It was noticed that animals were loaded forcefully although, there is recommended ramps for loading cattle. A non-adjustable ramp, for loading animals, should not exceed a slope of $20^{\circ}$ for cattle [13]. It should be noted that, although preslaughter stress usually starts during loading onto vehicles, in some cases it starts earlier than the loading time [14]. Separation of animals from their group and mixing of animals from different group are also stressful for animals.

In this study, from statistical analysis of available data, the travel distance $(p<0.3487)$ has no significant effect while animal number $(p<0.0498)$ has slightly significant effect on the occurrence of incidences such as animal death and injures, at the significance level of 0.05 . This indicates that the more animals transported by walking, the more the occurrence of such incidences. The effect of travel distance could be reflected well if other parameter such as weight loss has been considered.

From total number of animals transported to Gudar market about $7.6 \%$ died, about $6.9 \%$ injured and about 
2.8\% was stolen on the way. During transport from Gudar to Finfinnee city market by walking, from total number of animals about $16 \%$ died and $10.7 \%$ injured. Here, we want to mention that these figures were estimated based on limited amount of data and therefore the figures should be used with caution. Although the estimation (in the case of transport from Gudar to Finfinne) was based on data gained from only three traders, the result indicated that the percentage of death and injured animals were increased when compared with the case of transport from farm to Gudar. This increase indicated that the cumulative effect of long journey (from farm to Finfinne) increased the welfare concern of animals.

It was also observed that animals could be injured when forced to walk on asphalted road and the sharp gravel on the road which could injure animals' foot during long journey. In Nigeria about 34\% injuries were reportedly due to horns of cattle. In Bangladesh, during animal transport, injuries such as abrasion, scar, laceration, swelling, penetration, and bleeding were reported [14].

Lameness and injury to bone, muscle, swelling of leg and sickness were widely seen during transportation by walking. According to the report of Tegegne et al. [12] the development of market infrastructure and market institution in the country is very important to reduce such economic loss in the animal supply chain. There is significant amount of animal welfare concern in developing countries due to incidence of death, sickness and nonambulation of slaughter animals during transport to abattoir. Recent study in Ghana indicated that about 7\% of cattle supplied to an abattoir were downer animals [11].

During transport, as animals move from known to unknown environment, better animal handling and logistics management are required to improve animal welfare [15]. In Gudar market animals were grouped for better management. At Gudar market, animals were first mixed and categorized in to four groups: G1, G2, G3, and G4. Such grouping of animal were very essential for managing the market situation and controlling the animal health conditions and for identifying the potentially unhealthy animals from healthy ones. Grouping animals also allowed animals to adapt each other and creates stability and reduce restlessness and aggressiveness. Well trained handlers could move cattle efficiently and humanly [16]. Other problems of farmers and traders, noticed in this study were difficulties in getting timely market information, poor market infrastructure; and lack of links between farmers and traders.

Traders have more access of getting market price information than farmers. Farmers get market information mainly from earlier market and they usually go to the markets without information beforehand about the timely price of animals. Therefore, they may sometimes take back their animal if the price offered is below their expectation. This means wastage of time and exposing animal for more stressful conditions.

Animal welfare concerns such as fatigue, fear and distress, fasting, dehydration and injuries are more common in animals bought through livestock markets [14]. In Europe, selling slaughter animals through livestock markets is being discouraged due to problems such as inadequate level of traceability; transmission of disease; hide contamination; and poor welfare of animals sold in markets. Therefore, delivering animals directly to abattoir is widely encouraged $[14,17,18]$.

The slaughter operations at Ambo abattoir were identical with the traditional way of slaughtering by farmers. The only difference is the veterinary inspection. The waste from the slaughterhouse was simply discharged to the river. The abattoir operations need improvement taking into considerations the improvement of animal welfare, stunning system, hygienic conditions, and waste management.

One of the limitations of this study was the fact that the seasonal variation of animal flow was not investigated. Also some parameters such as weight loss due to transport and handling during transport was not measured and analyzed.

\section{Conclusions}

In this study, the animal handling and welfare issues during transport for marketing were investigated considering the case of the flow of cattle to and from Gudar livestock market and activity chain of Ambo abattoir in Ethiopia. This study identified that the animals were supplied to this central market mainly from 8 feeder markets and from local farmers. The flow of animals to Gudar market by walking took up to 4 days and it took up to $3 \mathrm{~h}$ by vehicles. Animals were traveled upto $319 \mathrm{~km}$ by walking from farm to Finfinnee market (the last destination), which took about 8 days. Such long journey has impact not only on animal welfare but also on meat safety and quality. There were no appropriate loading facilities and the vehicles were not designed for animal transport.

From total number of animals transported to Gudar market about $7.6 \%$ died, $6.9 \%$ injured and $2.8 \%$ was stolen on the way. During walking from Gudar to Finfinnee city market, from total number of animals about $16 \%$ died and $10.7 \%$ injured. Lameness and injury to bone and muscle; swelling of leg; and sickness were widely seen during the journey especially during journey by walking. Other problems of farmers and traders, noticed in this study were difficulties in getting timely market information; poor market infrastructure; and lack of links between farmers and traders.

In general, although Ethiopia has high potential of 
livestock resource, it gains less economic benefit due to unimproved production, lack of good marketing and abattoir systems in the regions of animal farms. Therefore, more research works should be carried out concerning animal welfare during transport to market or abattoir; in the market; pre/post-transport; and pre-slaughter; as well as studies concerning impact of abattoir activities on environment and human and animal health should be conducted. Such studies help to improve the economic benefits of livestock resources at both farm and national level.

\section{REFERENCES}

[1] B. Gebremadihin, D. Hoekstra and S. Jemaneh, "Heading toward Commercialization? The Case of Live Animal Marketing in Ethiopia,” International Livestock Research Institute, Improving Productivity and Market Success (IPMS) of Ethiopian Farmers Project Working Paper 5. ILRI (International Livestock Research Institute), Nairobi, Kenya, 2007.

[2] A. Solomon, A. Workalemahu, M. A. Jabbar, M. M. Ahmed and B. Hurissa, "Livestock Marketing in Ethiopia: A Review of Structure, Performance and Development Initiatives," Socio-Economics and Policy Research Working Paper 52, 2003.

http://www.fao.org/fileadmin/templates/agphome/images/ iclsd/documents/ wk2c5gerard.pdf

[3] G. Legese, H. Teklewold, D. Alemu and A. Negassa, "Live Animal and Meat Export Value Chains for Selected Area in Ethiopia, Constraints and Opportunities for Enhancing Meat Exports IRL Improving Market Opportunities,” International Livestock Research Institute, Discussion Paper 56, Nairobi, 2008.

[4] Y. Aklilu, "An Audit of the Livestock Marketing Status in Kenya, Ethiopia and Sudan,” Vol. 1, 2002. http://www.eldis.org/fulltext/cape_new/Akliliu_Marketin g_vol_1.pdf

[5] G. Gebresenbet, T. G. Bosona, D. Ljungberg and S. Aradom, "Optimisation Analysis of Large and Small-Scale Abattoirs in Relation to Animal Transport and Meat Distribution," Australian Journal of Agricultural Engineering, Vol. 2, No. 2, 2011, pp. 31-39.

[6] F. J. Kenny and P. V. Tarrant, "The Reaction of Young Bulls to Short-Haul Road Transport," Applied Animal Behaviour Science, Vol. 17, No. 3, 1987, pp. 209-227. doi:10.1016/0168-1591(87)90147-X

[7] G. A. Maria, M. Villarroel, G. Chacon and G. Gebresenbet, "Scoring System for Evaluating the Stress to Cattle of Commercial Loading and Unloading," Veterinary Record, Vol. 154, 2004, pp. 818-821. doi:10.1136/vr.154.26.818

[8] D. M. Broom, "Welfare Assessment and Welfare Problem Areas during Handling and Transport," CAB International, Wallingford, 1993.

[9] G. Gebresenbet, W. Baltussen, K. Roest, K. Neilson and P. Sterrenburg, "Evaluation of the Feasibility of a Certification Scheme for High Quality Control Posts,” 2010. http://ec.europa.eu/food/animal/welfare/financing/docs/ca Il_10753-2010_feasability_report_cepost_en.pdf

[10] D. Ljungberg, G. Gebresenbet and S. Aradom, "Logistics Chain of Animal Transport and Abattoir Operations," Biosystems Engineering, Vol. 96, No. 2, 2007, pp. 267277. doi:10.1016/j.biosystemseng.2006.11.003

[11] S. Frimpong, "Effect of Pre-Slaughter Handling and Transport on Welfare and Meat Quality of Cattle: A Case Study of Kumasi Abattoir," Master's Thesis, Kwame Nkrumah University of Science and Technology, Kumasi, 2009.

[12] A. Tegegne, B. G. Berhanu and D. Hoekstra, "Input Supply System and Services for Market-Oriented Livestock Production in Ethiopia," Improving Productivity and Marketing Success (IPMS) Project, ILRI, Addis Ababa, 1997.

[13] T. Grandin, "Design of Loading and Holding Pens," Applied Animal Behavior Science, Vol. 28, No. 1-2, 1990, pp. 187-201.

[14] N. G. Gregory, “Animal Welfare at Markets and during Transport and Slaughter,” Meat Science, Vol. 80, No. 1, 2008, pp. 2-11. doi:10.1016/j.meatsci.2008.05.019

[15] A. Tegegne, B. Gebremedhin and D. Hoekstra, "Input Supply System and Services for Market-Oriented Livestock Production in Ethiopia," Proceedings of the 14th Annual Conference of the Ethiopian Society of Animal Production (ESAP), Addis Ababa, September 5-7 2006.

[16] S. Atkinson, "The Importance of Animal Handling Technique and Animal Handling Facility Design for the Welfare of Slaughter Animals,” NJF Report, Vol. 1, No. 4, 2005.

[17] M. S. Cockram, "Criteria and Potential Reasons for Maximum Journey Times for Farm Animals Destined for Slaughter,” Applied Animal Behavior Science, Vol. 106, No. 4, 2007, pp. 234-243. doi:10.1016/j.applanim.2007.01.006

[18] J. N. Sofos, "Challenges to Meat Safety in $21^{\text {st }}$ Century," Meat Science, Vol. 78, No. 1-2, 2008, pp. 3-13. doi:10.1016/j.meatsci.2007.07.027 